\title{
Some Properties of the Polyamine Deprivation-inducible Uptake System for Methylglyoxal Bis(guanylhydrazone) in Tumor Cells
}

\author{
P. SEPPÄNEN
}

Department of Biochemistry, University of Helsinki, SF-00170 Helsinki 17, Finland

Intracellular polyamine deprivation, produced by DL- $\alpha$-difluoromethylornithine (DFMO), resulted in a striking enhancement of cellular transport of the natural polyamines and methylglyoxal bis(guanylhydrazone) (MGBG). In addition to the natural polyamines and MGBG, the uptake of other diamines and triamines was likewise enhanced in response to DFMO, although longer than threecarbon backbone was required for about 10-fold stimulation to occur. Intracellular deprivation of polyamines did not increase the affinity of the transport system for MGBG but greatly enhanced the maximum velocity of the drug transport. The uptake process of MGBG was temperature dependent and the activation energy $\left(E_{\mathrm{a}}=67.5 \mathrm{~kJ}\right)$ for the uptake system was the same for both the polyamine-depleted tumour cells and for the untreated cells. The uptake of the drug appeared to be more dependent on the $\mathrm{Na}^{+}$-linked uptake, as indicated by the inhibitory effect of ouabain, than on energy production. Deprivation of putrescine and spermidine changed the intracellular distribution of MGBG since a major portion of the drug was concentrated in the microsomal fraction in polyamine-depleted cells.

DFMO is an irreversible inhibitor of ornithine decarboxylase (EC 4.1.1.17), ${ }^{1}$ the key enzyme in the biosynthesis of the polyamines. It is one of the most potent inhibitors of putrescine and spermidine formation in eukaryotic cells. ${ }^{2}$ An exposure of a great variety of mammalian cell types to millimolar concentrations of DFMO leads to an almost complete depletion of cellular putrescine and spermidine. $^{3-5}$

A deprivation of putrescine and spermidine in Ehrlich ascites carcinoma cells has recently been shown to result in an enhancement of the uptake of the natural polyamines and $\mathrm{MGBG}^{6}$ The enhanced uptake of the natural polyamines during polyamine depletion apparently is one of the compensatory mechanisms by which cells attempt to restore their intracellular polyamine pools. MGBG is a structural analogue of spermidine, apparently sharing a common transport system with the natural polyamines ${ }^{7,8}$ which means that polyamine deprivation also leads to a dramatic increase of the uptake of the drug. Not only was the uptake of MGBG enhanced in polyamine-depleted Ehrlich ascites carcinoma cells but a previous treatment with DFMO until depletion of putrescine and spermidine also potentiated the antiproliferative action of MGBG both in vitro and in vivo. ${ }^{9}$

In this report the uptake system for MGBG, induced by the treatment of Ehrlich ascites carcinoma cells with DFMO until putrescine and spermidine depletion, has been partly characterized.

\section{MATERIALS AND METHODS}

Cell cultures. Ehrlich ascites carcinoma cells were grown in suspension cultures in RPMI 1640 medium (Orion Diagnostica, Helsinki, Finland) supplemented with $5 \%(\mathrm{v} / \mathrm{v})$ pooled human serum (Finnish Red Cross Transfusion Service, Helsinki, Finland) and $50 \mu \mathrm{g} / \mathrm{ml}$ of both penicillin and streptomycin. Cells were harvested by low speed centrifugation and washed with $2 \mathrm{ml}$ of physiological saline.

Chemicals. S-Adenosyl-L $\left(1-{ }^{14} \mathrm{C}\right)$ methionine was prepared enzymatically by the method of Pegg and Williams-Ashman. ${ }^{10}$ Methylglyoxal bis(guanylhydrazone) was obtained from Ega-Chemie (Steinheim/Albuch, West Germany). Putrescine, sper- 
midine, spermine and 1,5-diaminopentane were purchased from Calbiochem (San Diego, CA, U.S.A.). 1,2-Diaminoethane and 1,6-diaminohexane were products of BDH Chemicals (Poole, Dorset, U.K.). 1,3-Diaminopropane and 1,7-diaminoheptane were obtained from Fluka A.G. (Buchs SG, Switzerland). 3,3'-Iminobispropylamine (3,3'-diaminodipropylamine) was a product of Aldrich-Europe (Beerse, Belgium). $N$-Acetylputrescine, $N^{1}$-acetylspermidine and $N^{8}$-acetylspermidine were kindly supplied by Dr. N. Seiler (Centre de Recherche Merrell International, Strasbourg, France) and DL- $\alpha$-difluoromethylornithine was a generous gift from the Centre de Recherche Merrell International.

Analytical methods. Cellular concentrations of various amines were determined from perchloric acid extracts after dansylation by the method of Seiler ${ }^{11}$ with the modifications introduced by Dreyfuss et al., ${ }^{12}$ using chloroform-dioxanbutan-1-ol ( $48: 1: 1$, by volume) as the solvent. The uptake of 1,4-diaminobut-2-ene, 1,6-diaminohexane and the natural polyamines was calculated as a net uptake by subtracting from the respective fraction the part that has increased during a 2-h uptake.

Cell densities were measured with an electronic particle counter (Coulter Electronics Ltd, Harpenden, U.K.). Cell volumes (for calculation of intracellular MGBG concentrations) were measured with the counter as described in the instruction manual.

For the MGBG assay, cells were suspended in physiological saline and disintegrated ultrasonically. The concentration of MGBG in sonicates was determined by the method previously described by Seppänen et al. ${ }^{13}$ The cellular ATP content was measured with a Lumac Celltester M 1030 (Lumac Systems A.G., Basel, Switzerland). The protein content in cell fractions was measured by the method of Lowry et al. ${ }^{14}$

Cell fractionation. Osmotic shock $(10 \mathrm{~min}$ in $5 \mathrm{mM}$ Tris- $\mathrm{HCl}$ buffer, $\mathrm{pH} 7.1,1 \mathrm{mM}$ mercaptoethanol, $2 \mathrm{mM} \mathrm{CaCl}$ ) was used to achieve better disintegration. Cells were homogenized with a Dounce homogenizer with tight-fitting pestle (15 strokes) under microscope control. Homogenates were centrifuged for $10 \mathrm{~min}, 1000 \times g$, to obtain the crude nuclear fraction. From the remaining supernatant fractions mitochondria were sedimented at $15000 \times g$ for $15 \mathrm{~min}$. Microsomes were sedimented at $100000 \times g$ for $1 \mathrm{~h}$. Fractions were suspended in physiological saline and sonicated prior to the MGBG assay. Although the results were mainly obtained from single experiments, their reproducibility under standard conditions has been confirmed several times.

Table 1. Net uptake of various amines and MGBG in Ehrlich ascites carcinoma cells. Ehrlich ascites carcinoma cells were grown in the absence or presence of $3 \mathrm{mM}$ DFMO for $48 \mathrm{~h}$ whereafter the cells were exposed to $5 \mu \mathrm{M}$ MGBG or to the various amines indicated and cellular contents of the drug or these amines were measured $2 \mathrm{~h}$ later.

\begin{tabular}{lll}
\hline Addition & $\begin{array}{l}\text { Net uptake }\left(\mathrm{nmol} / 10^{6} \text { cells }\right) \\
\text { Untreated } \\
\text { cells }\end{array}$ & $\begin{array}{l}\text { DFMO-treated } \\
\text { cells }\end{array}$ \\
\hline Putrescine & 0.14 & 1.75 \\
Spermidine & $\mathrm{ND}^{a}$ & 3.08 \\
Spermine & $\mathrm{ND}^{a}$ & 2.17 \\
MGBG & 0.15 & 1.81 \\
1,2-Diaminoethane & 0.24 & 0.47 \\
1,3-Diaminopropane & 0.30 & 0.61 \\
1,4-Diaminobutene & $\mathrm{ND}^{a}$ & 0.93 \\
1,5-Diaminopentane & 0.15 & 1.50 \\
1,6-Diaminohexane & 0.22 & 2.92 \\
1,7-Diaminoheptane & 0.38 & 1.75 \\
3,3'-Iminobispropylamine & 0.37 & 4.01 \\
$N$-Acetylputrescine & $\mathrm{ND}^{a}$ & $\mathrm{ND}$ \\
$N^{1}$-Acetylspermidine & 0.34 & 1.80 \\
$N^{8}$-Acetylspermidine & 0.12 & 0.43 \\
\hline
\end{tabular}

${ }^{a}$ Not detected. 


\section{RESULTS}

Effect of DFMO on the uptake of the natural polyamines, MGBG and some diamines. When Ehrlich ascites carcinoma cells were exposed to 3 $\mathrm{mM}$ DFMO for $48 \mathrm{~h}$, the intracellular putrescine concentration decreased to an undetectable level and the spermidine concentration to $0.09 \mathrm{nmol} / 10^{6}$ cells, which was less than $5 \%$ of the normal polyamine content of these tumour cells.

As shown in Table 1, the uptake system induced by polyamine deprivation was not entirely specific for the natural polyamines and MGBG. A more than 10-fold enhancement of the uptake of diamines with a backbone longer than three-carbon was seen. 1,4-Diaminobutene was taken up by the polyaminedepleted tumour cells almost as effectively as the natural diamine putrescine, and also metabolized further to the respective spermidine analogue. A dramatic stimulation of the uptake of 1,5-diaminopentane, 1,6-diaminohexane and 1,7-diaminoheptane also occurred. The best substrate of the uptake system induced after DFMO treatment appeared to be 3,3'-iminobispropylamine which was concentrated by the cells even more effectively than the natural polyamine spermidine.

Regarding the acetylated derivatives, only the uptake of $N^{1}$-acetylspermidine was markedly enhanced after treatment with DFMO. $N^{1}$-Acetylspermidine has a free putrescine moiety, which is obviously required for uptake since $N$-acetylputrescine was not taken into the cells at all and $N^{8}$ acetylspermidine to a much lesser extent than the $N^{1}$-acetylated form of the compound. Under the same experimental conditions, the uptake of radioactive lysine and leucine was not stimulated by a 48-h treatment with DFMO and the uptake of methionine, arginine and ornithine was only 1,4fold faster in polyamine-depleted tumour cells than in untreated tumour cells (results not shown).

Effect of MGBG concentration. The effect of MGBG concentration was studied by exposing Ehrlich ascites carcinoma cells to various concentrations of MGBG (from 2 to $50 \mu \mathrm{M}$ ) for $30 \mathrm{~min}$ whereafter intracellular concentrations of the drug were determined. The system was not saturable even at high extracellular concentrations, which indicated that passive diffusion was also involved in the transport process and may be predominant at higher extracellular concentrations.

Kinetic parameters, $K_{\mathrm{m}}$ and $V_{\max }$ values, for the uptake of MGBG by polyamine-depleted cells and untreated tumour cells were obtained from Lineweaver-Burk graphs. Lineweaver-Burk plots were taken from the theoretical concentration curves which were obtained by subtracting from experimental concentration curves the part which obviously represented passive diffusion by the method of Winter and Christensen. ${ }^{15}$

Deprivation of polyamines in Ehrlich ascites carcinoma cells did not influence the affinity of the transport system for MGBG since the $K_{\mathrm{m}}$ values were about the same for untreated tumour cells and for cells previously treated with DFMO for $48 \mathrm{~h}$ ( $K_{\mathrm{m}} 3.2$ and $2.6 \mu \mathrm{M}$, respectively). However, the maximum velocity for the uptake of the drug was four times higher in polyamine depleted cells $\left[V_{\max } 20.4 \mathrm{pmol} /\left(10^{6}\right.\right.$ cells $\left.\left.\min \right)\right]$ compared with that in untreated cells $\left[V_{\max } 4.7 \mathrm{pmol} / 10^{6} /\right.$ (cells $\min )$ ].

Effect of temperature, ouabain and iodoacetate on the uptake of $M G B G$. The effect of temperature on the uptake of MGBG was studied at four different temperatures $\left(4,15,25\right.$ and $\left.37^{\circ} \mathrm{C}\right)$. Cells were

Table 2. Effect of ouabain and iodoacetate on MGBG uptake. Cells were grown in the absence or presence of $3 \mathrm{mM}$ DFMO for $48 \mathrm{~h}$ whereafter either ouabain $(0.75 \mathrm{mM})$ or iodoacetate $(0.2 \mathrm{mM})$ was added to the medium prior to MGBG $(5 \mu \mathrm{M})$. Intracellular concentrations of the latter drug were determined after $2 \mathrm{~h}$ uptake.

\begin{tabular}{llcccc}
\hline Treatment & Addition & \multicolumn{2}{c}{$\begin{array}{l}\text { Intracellular MGBG } \\
\text { concentration } \\
(\mu \mathrm{M})\end{array}$} & $\begin{array}{l}\text { Cellular ATP } \\
\text { concentration } \\
(\mathrm{pg} / \text { cell) }\end{array}$ \\
\hline None & MGBG & 382 & $(100 \%)$ & 1.25 & $(100 \%)$ \\
None & MGBG + Ouabain & 126 & $(33 \%)$ & 0.99 & $(79 \%)$ \\
None & MGBG + Iodoacetate & 207 & $(54 \%)$ & 0.10 & $(8 \%)$ \\
DFMO & MGBG & 2970 & $(100 \%)$ & 1.65 & $(100 \%)$ \\
DFMO & MGBG + Ouabain & 1770 & $(60 \%)$ & 1.48 & $(89 \%)$ \\
DFMO & MGBG + Iodoacetate & 2651 & $(89 \%)$ & 0.38 & $(23 \%)$ \\
\hline
\end{tabular}

Acta Chem. Scand. B 35 (1981) No. 10 


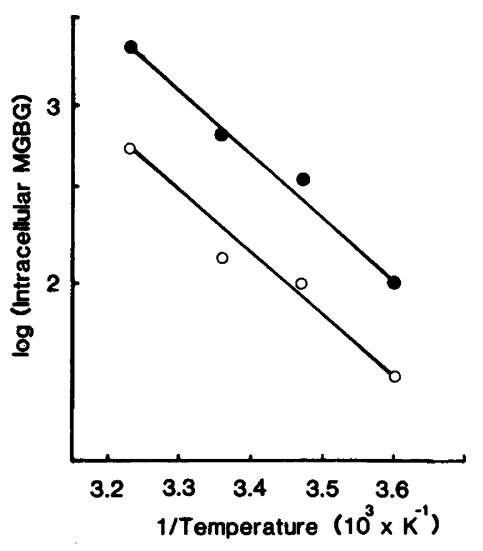

Fig. 1. Effect of temperature on the uptake of MGBG in Ehrlich ascites carcinoma cells. Ehrlich ascites carcinoma cells were cultured in the absence or presence of $3 \mathrm{mM}$ DFMO for $48 \mathrm{~h}$ whereafter the cells were harvested by centrifugation, suspended in culture medium at $4,15,25$ or $37^{\circ} \mathrm{C}$, and exposed to $5 \mu \mathrm{M}$ MGBG. The intracellular concentrations of the drug were determined after $4 \mathrm{~h}$. The activation energy of the uptake was calculated from the Arrhenius equation. $O$, untreated cells; , cells treated with DFMO.

exposed to $5 \mu \mathrm{M}$ MGBG for $4 \mathrm{~h}$ whereafter the intracellular concentration of the drug was determined. As shown in Fig. 1, the uptake of the drug was temperature-dependent both in the polyaminedepleted tumour cells and in the cells containing normal polyamine pools. The activation energy of the uptake process remained the same $\left(E_{\mathrm{a}} 67.5 \mathrm{~kJ}\right)$ irrespective of a previous treatment with DFMO (Fig. 1). The uptake of the drug was dependent not only on temperature but ouabain, an inhibitor of $\mathrm{Na}^{+}, \mathrm{K}^{+}$-ATPase, also decreased the uptake by almost $70 \%$ in untreated cells and by $40 \%$ in polyamine-depleted cells (Table 2). The ouabain concentration used in this experiment had little effect on the cellular content of ATP. This result suggests that the uptake of MGBG is partly dependent on an $\mathrm{Na}^{+}$-linked uptake.

Iodoacetate that decreased cellular ATP content more than $90 \%$ in untreated cells and by $80 \%$ in DFMO-treated cells inhibited the uptake of MGBG much less than did ouabain. Only $10 \%$ inhibition of the uptake of MGBG was seen in polyaminedepleted tumour cells, while in cells with normal polyamine pattern the inhibition produced by iodoacetate was about $40 \%$ (Table 2). The ouabain and iodoacetate concentrations used in this experiment had no effect on cell viability as tested by a dye exclusion test.

Subcellular distribution of MGBG. When Ehrlich ascites carcinoma cells were exposed to $5 \mu \mathrm{M}$ MGBG for $12 \mathrm{~h}$ the intracellular concentration was $3 \mathrm{mM}$ in the cells containing normal putrescine and spermidine contents. A treatment with $3 \mathrm{mM}$ DFMO for $48 \mathrm{~h}$ before the cells were exposed to MGBG greatly enhanced the concentrating capacity of the cells so that the intracellular concentration of the drug was over $9.5 \mathrm{mM}$.

All the cell fractions of polyamine-depleted cells appeared to contain more MGBG than the cells not previously treated with DFMO. Although in the DFMO-treated cells nuclear, mitochondrial and cytosol fractions contained 3-4 times more drug than those of untreated cells, MGBG appeared to be concentrated most effectively in the microsomal fraction in polyamine-depleted cells (Fig. 2). In these cells the microsomal MGBG content was more than 7 times higher $(150 \mathrm{nmol} / \mathrm{mg}$ protein $)$ than in the microsomal fraction of the cells having normal intracellular polyamine pools $(20 \mathrm{nmol} / \mathrm{mg}$ protein) (Fig. 2).

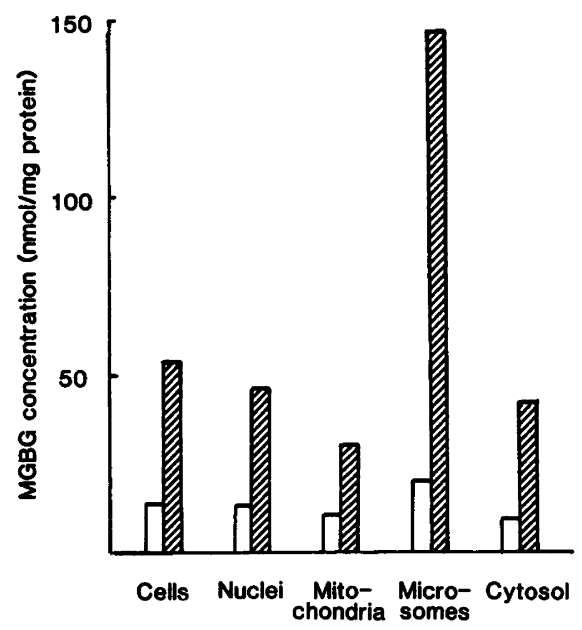

Fig. 2. Subcellular distribution of MGBG in Ehrlich ascites carcinoma cells. Ehrlich ascites carcinoma cells were grown in the absence or presence of $3 \mathrm{mM}$ DFMO for $48 \mathrm{~h}$ whereafter the cells were exposed to $5 \mu \mathrm{M}$ MGBG for $12 \mathrm{~h}$. Cells were fractionated as described in the text and the drug concentrations in the fractions were measured. $\square$, untreated cells; $\square$, cells treated with DFMO. 


\section{DISCUSSION}

Deprivation of putrescine and spermidine by DFMO in Ehrlich ascites carcinoma cells results in a dramatic stimulation of the transport system of the natural polyamines and MGBG. ${ }^{6}$ As found here the transport system induced during polyamine depletion appeared not to be entirely specific for the natural polyamines or MGBG. Results shown in Table 1, suggested that diamines longer than three carbon atoms and $N^{1}$-acetylspermidine also used the same stimulated uptake system.

Intracellular deprivation of polyamines in Ehrlich ascites carcinoma cells did not affect the affinity of the uptake system for MGBG. However, the maximum velocity of the uptake of the drug was four times higher in polyamine-depleted cells compared with that in the cells that had a normal polyamine pool. L1210 mouse leukemia cells resistant to MGBG had a 15-fold lower affinity for the drug than normal L1210 cells, while the maximum velocity for the uptake of the drug was the same for both cell lines. ${ }^{8}$ These facts may be taken as indirect evidence that the enhancement of the uptake of MGBG in polyamine-depleted Ehrlich ascites carcinoma cells was not caused by an increased number of receptor sites in the cell membrane but possibly by an increased number of intracellular binding sites for the drug.

The uptake of MGBG appeared to be partly dependent on $\mathrm{Na}^{+}$-linked uptake since the $\mathrm{Na}^{+}$, $\mathrm{K}^{+}$-ATPase inhibitor ouabain markedly decreased the uptake of the drug in both the DFMO-treated cells and in untreated cells (Table 2).

When the cellular ATP content was reduced by non-toxic concentration of iodoacetate the uptake of MGBG was only marginally decreased in polyamine-depleted cells although the concentration gradient across the cell membrane was more than 500 -fold. The same iodoacetate concentration caused about $40 \%$ inhibition of the uptake of the drug while in untreated cells the concentration gradient that was formed between cell membrane was not more than 80 -fold. These results suggest that energy production was not absolutely required for maintaining the concentration gradient that had formed. It was more likely that the drug was intracellularly bound.

MGBG can be considered as a structural analogue of spermidine and therefore it obviously displays high affinity for the same structures as do polyamines. Accordingly, the observed dramatic en- hancement of the uptake of MGBG after the treatment with DFMO could at least partly be caused by a decrease in total intracellular polycations. The microsomal fraction appeared to concentrate or bind the drug most effectively in the polyaminedeprived cells although the content of the drug was 3- to 4-fold higher also in other cell fractions (Fig. 2).

Although the mechanisms of antiproliferative action of MGBG is not exactly known, several lines of evidence suggest that the observed inhibition of adenosylmethionine decarboxylase (EC 4.1.1.50) ${ }^{16}$ is not the only way the drug affects cells proliferation. Early changes in mitochondrial morphology have been reported in MGBG-treated L1210 cells far before any depletion of intracellular spermidine concentration could be seen. ${ }^{17}$ Morphological changes in other cell organelles have not been noticed but millimolar concentrations of the drug have been shown to affect different cellular functions directly. An inhibition of DNA synthesis, ${ }^{18}$ of template activity of chromatine, ${ }^{19}$ of oxidative phosporylation and cell respiration ${ }^{20}$ and of RNA polymerase activity ${ }^{21}$ have been reported in the presence of millimolar MGBG concentrations.

The finding that polyamine depletion induces or stimulates the uptake of extracellular polyamines and related molecules can be used to achieve rapid antiproliferative action upon an exposure to MGBG and some other cytotoxic compounds, which are structural analogues of the natural polyamines. 3,3'Iminobispropylamine, which was taken into the polyamine-depleted cells even faster than the natural polyamines or MGBG (Table 1), also possessed an antiproliferative action stronger than that of MGBG (results not shown).

Acknowledgements. The skilfull technical assistance of Ms Raija Laine is gratefully acknowledged. I thank Associate Professor J. Jänne for his help during the work and in preparation of the manuscript. This work received financial support from the Emil Aaltonen Foundation (Tampere, Finland) and from the Ida Montin Foundation (Helsinki, Finland).

\section{REFERENCES}

1. Metcalf, B. W., Danzin, C., Jung, M. J., Casara, P. and Vevert, J. P. J. Am. Chem. Soc. 100 (1978) 2551. 
2. Heby, O. and Jänne, J. In Morris, D. R. and Marton, L. J., Eds., Polyamines in Biology and Medicine, Dekker, New York 1981, pp. 243310.

3. Mamont, P. S., Duchesne, M.-C., Grove, J. and Bey, P. Biochem. Biophys. Res. Commun. 193 (1978) 58.

4. Hölttä, E., Jänne, J. and Hovi, T. Biochem. J. $178(1979) 109$.

5. Seidenfeld, J. and Marton, L. J. Biochem. Biophys. Res. Commun. 86 (1979) 259.

6. Alhonen-Hongisto, L., Seppänen, P. and Jänne, J. Biochem. J. 192 (1980) 941.

7. Dave, C. and Caballes, L. Fed. Proc. Fed. Am. Soc. Exp. Biol. 32 (1973) 736.

8. Mihich, E., Dave, C. and Williams-Ashman, $\mathrm{H}$. G. In Daikos, G. K., Ed., Prog. Chemother., Prog. Int. Congr. Chemother. 8th, Hellenic Society for Chemotherapy, Athens 1974, Vol. 3, pp. 845-848.

9. Seppänen, P., Alhonen-Hongisto, L. and Jänne, J. Biochem. Biophys. Acta 674 (1981) 169.

10. Pegg, A. E. and Williams-Ashman, H. G. J. Biol. Chem. 244 (1969) 682.

11. Seiler, N. Methods Biochem. Anal. 18 (1970) 259.

12. Dreyfuss, G., Dvir, R., Harell, A. and Chayen, R. Clin. Chim. Acta 49 (1973) 65.

13. Seppänen, P., Alhonen-Hongisto, L., Pösö, H. and Jänne, J. FEBS Lett. 111 (1980) 99.

14. Lowry, O. H., Rosebrough, N. J., Farr, A. L. and Randall, R. J. J. Biol. Chem. 193 (1951) 265.

15. Winter, C. G. and Christensen, H. N. J. Biol. Chem. 239 (1964) 872.

16. Williams-Ashman, H. G. and Schenone, A. Biochem. Biophys. Res. Commun. 46 (1972) 288.

17. Pleshkewych, A., Kramer, D. L., Kelly, E. and Porter, C. W. Cancer Res. 40 (1980) 4533.

18. Knutson, J. C. and Morris, D. R. Biochim. Biophys. Acta 478 (1978) 417.

19. Brown, K. B., Nelson, N. F. and Brown, D. G. Biochem. J. 151 (1975) 505.

20. Pine, M. J. and DiPaolo, J. A. Cancer Res. 26 (1966) 18.

21. Nelson, N. F., Brown, K. B., Fehlman, B. R., Stewart, G. P. and Brown, D. G. Biochim. Biophys. Acta 517 (1978) 428.

Received August 10, 1981. 